\title{
The influence of iron losses on selecting the minimum excitation capacitance for self-excited induction generator (SEIG) with wind turbine
}

\author{
Hayder Hussein Kadhum ${ }^{1}$, Ahmed Samawi Alkhafaji ${ }^{2}$, Hayder H. Emawi ${ }^{3}$ \\ ${ }^{1,2}$ Department of Electrical Engineering, University of Babylon, Iraq \\ ${ }^{3}$ Department of Biomedical Engineering, University of Babylon, Iraq
}

\begin{tabular}{|c|c|}
\hline Article Info & ABSTRACT \\
\hline Article history: & The capacitance selection of the three-phase self-excited induction generators \\
\hline Received Aug 6, 2019 & (SEIG) driven by wind energy is influences by the iron losses. This paper \\
\hline Revised Jan 1, 2020 & of the generator supplying an induction oil pump. No previous literature \\
\hline Accepted Jan 13, 2020 & studying the requirements of selecting the minimum excitation capacitance \\
\hline & $\begin{array}{l}\text { under the iron loss impact is found. This work is focusing on: (i) a novel } \\
\text { evaluation of the characteristics of the induction generator taking iron loss }\end{array}$ \\
\hline Keywords: & into account. (ii) the errors caused by neglecting the iron loss. \\
\hline Iron loss & (iii) the importance of including the iron-loss in any accurate analysis. \\
\hline Minimum excitation & $\begin{array}{l}\text { (iv) the errors occurred in the selection of the precise excitation capacitance } \\
\text { (Cexct) when the iron-loss neglected. Nodal analysis is suggested to describe }\end{array}$ \\
\hline capacitance & the study-state performance of the proposed model. A Matlab/simulation \\
\hline $\begin{array}{l}\text { Self-excited induction } \\
\text { generators (SEIG) }\end{array}$ & is established to validate the proposed model. \\
\hline
\end{tabular}

Copyright () 2020 Institute of Advanced Engineering and Science. All rights reserved.

\section{Corresponding Author:}

Ahmed Samawi Alkhafaji,

Department of Electrical Engineering,

University of Babylon, Babylon, Hilla, Iraq.

Email: ahmed.samawi2019@gmail.com

\section{INTRODUCTION}

The SEIG usage was started at $20^{\text {th }}$ century, at its earlier years till 1960 were its almost disappeared [1]. At the 1970s, the petroleum and gas prices were dramatically increased which is causing a return to the use of induction generators (IG). Using IG in a wind power generation system is having many positive returns in comparison to the conventional synchronous generators. It is simple, robust, dependable, economy, lightweight, long lasting (50 years). IG is suitable for little wind and hydro power plants [2, 3]. The negativity of IG is its low power-factor and poorness in the regulating of frequency and voltage regulation. Connecting IG to a network can contribute $100 \mathrm{kw}$ or more [1]. A turbine (regulated and unregulated) driving SEIG to supply a load (static or dynamic) has been thoroughly discussed by many researchers [4-5]. A three-phase induction machine operation studying at a study-state is basically depending on the per-phase equivalent circuit analysis and on either the loop impedance [5-13]. To operate the SEIG a necessary magnetic field is needed to convert the machine shaft's mechanical power to electrical. The needed active power which is generating this magnetic field is externally produced. This is provided by externally reactive source connected permanently to the stator windings of the IG. If IG is externally connected to capacitors, the machine is called SEIG. The engine shaft is rotated by an external force. The residue of magnetic field, with this movement, is inducing a voltage across capacitors, the result is a current passing through a parallel circuit. This current is reinforcing the magnetic field and an excitation is increasingly building up. The SEIG is usually used in a minor power-plant because of the capacitors high cost and a maintenance needs [5]. 
None of the [7] and [14-16] is considering the notable iron losses effect in the d-q axis model and steady state operation of SEIG. For the more accuracy of the predicted behavior of the SEIG, there is a great need to take this effects in consideration especially when the wind energy is driving the machine. A model of enhanced IG which is taking the iron losses in consideration is suggested in this paper. The losses are a function of air-gap flux and a stator frequency. The machine performance analysis is done at various operating conditions. Most times, the effects of the iron-losses are excluded for simplicity which will resulting in a non-accurate analysis. In fact, the iron-losses effect is having a non-negligible impact on the SEIG operation.

\section{Problem Statement}

Power production using wind-turbine is depending on the speed of the wind. The excitation capacitance of the SEIG driven by a wind turbine is an essential part and needs to be accurately calculated. Many papers were published regarding discussing this issue. Most of them are neglecting an important factor in the calculations. The iron losses is having a noticeable effect on choosing the excitation capacitance and must not be neglected for a highly accurate calculation. This work is studying and analyzing the mathematical model of the SEIG system using MatLab software which is tacking the iron losses effects into consideration especially at low wind speeds.

\section{Proposed System}

The projected power generating system is consisting of SEIG which is actuated by a wind turbine. The SEIG is linked to an exciting capacitor externally. This system is feeding a $1.5 \mathrm{KW}$ induction oil pump load as in Figure 1. The used SEIG's parameters was exactly measured by testing the induction generator when using it as a motor [17-19].

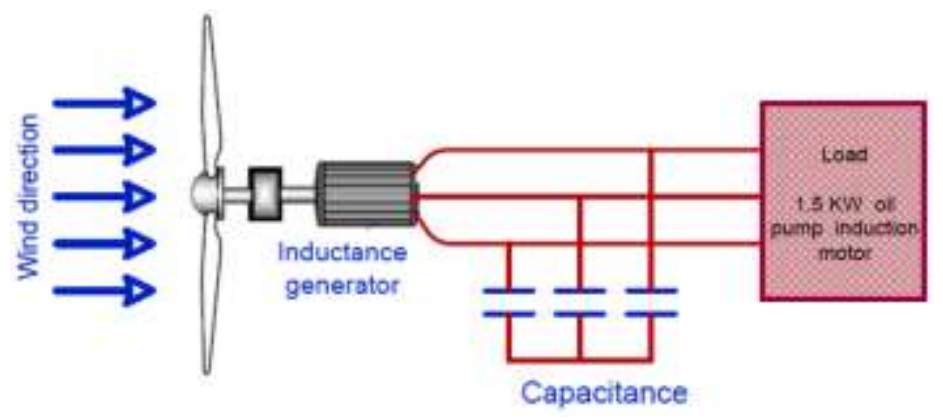

Figure 1. Model of SEIG driven by wind turbine

\section{MATHEMATICAL ANALYSIS OF SEIG WITH IRON LOSSES}

In order to find the required capacitance value, nodal analysis is used which does not need to calculate $X_{c}$ as in loop technique. The frequency due to the resultant equation $Y_{t}=0$ is deduced from the equation real part which is used in the imaginary part to calculate the capacitance. The per-phase equivalent Circuit of (SEIG) with equivalent iron-loss resistance is shown in Figure 2 and the nodal admittance equations are found from the equivalent circuit in Figure 2.

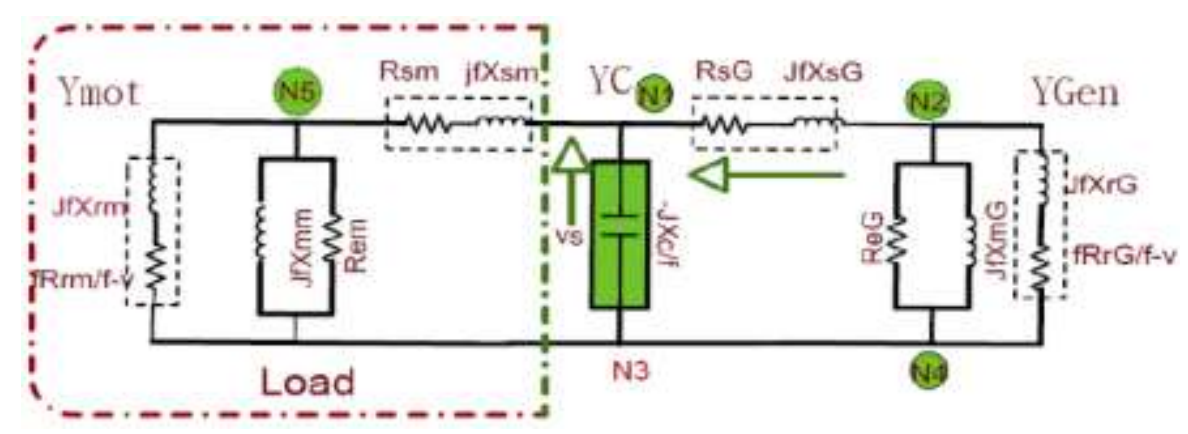

Figure 2. SEIG with equivalent iron loss resistance 
YGen, Ymot have been formed as follows:

$$
\begin{aligned}
Y_{G e n} & =\frac{1}{R_{S G}+j X_{S G}+\left[\left(R_{e G} / / j X_{m G}\right) / /\left(j X_{r G}+\frac{R_{r G}}{f-v}\right)\right]} \\
Y_{m o t} & =\frac{1}{R_{s m}+j X_{S m}+\left[\left(R_{e m} / / j X_{m m}\right) / /\left(j X_{r m}+\frac{R_{r m}}{f-v}\right)\right]}
\end{aligned}
$$

And:

$$
Y_{C}=\frac{1}{-j X_{C}}
$$

At node "N1" in Figure 2, the relation between IM , IG and IC can be written as:

$$
I_{M}+I_{C}-I_{G}=0
$$

The above equation can be expressed as follows:

$$
V\left(Y_{M}+Y_{G}+Y_{C}\right)=0
$$

The real as well as imaginary parts of the admittance are zeros at steady-state excitation Vs $\neq 0$ :

$$
\left(Y_{M}+Y_{G}+Y_{C}\right)=0
$$

Equation 5 can be separated for real and imaginary parts as follows:

$$
\left[\begin{array}{l}
R_{e}\left(Y_{M}+Y_{G}+Y_{C}\right)=0 \\
I_{m}\left(Y_{M}+Y_{G}+Y_{C}\right)=0
\end{array}\right]
$$

During steady-state situation $I \neq 0$. As a result, $Y=0$, equating real and imaginary parts of $Y$ to zeroes. The real part yields

$$
P\left(X_{m}, F\right)=\left(A_{1} X_{m}+A_{2}\right) F^{3}+\left(A_{3} X_{m}+A_{4}\right) F^{2}+\left(A_{5} X_{m}+A_{6}\right) F+\left(A_{7} X_{m}+A_{8}\right)
$$

Coefficients A1 to A8 can be determined as shown in Appendix 1. Xm is chosen equal to Xmsat and (7) is an equation with unknown $\mathrm{XC}$. Other equations are obtained and trial and error procedure is followed to determine relation between $\mathrm{XC}$ and $\mathrm{Xm}$. When (7) is rearranged versus $\mathrm{XC}$, the following equation is obtained:

$$
-a_{1} F^{3}+a_{2} F^{2}+\left(a_{3} X_{c}+a_{4}\right) F-a_{5} X_{c}=0
$$

where a1 to a5 are calculated as shown in Appendix 1. From (8):

$$
X_{c}=\frac{a_{1} F^{3}-a_{2} F^{2}-a_{4} F}{a_{3} F-a_{5}}
$$

If the imaginary part of (6) is put equal to zero, then:

$$
Q\left(X_{m}, F\right)=\left(B_{1} X_{m}+B_{2}\right) F^{4}+\left(B_{3} X_{m}+B_{4}\right) F^{3}+\left(B_{5} X_{m}+B_{6}\right) F^{2}+\left(B_{7} X_{m}+B_{8}\right) F+B_{9}
$$

Coefficients of $\mathrm{Xm}$ are calculated as reported in Appendix 1. Eqn. (10) can be written versus $\mathrm{X}_{\mathrm{C}}$ as follows:

$$
\begin{aligned}
& -b_{1} F^{4}+b_{2} F^{3}+\left(b_{3} X_{c}+b_{4}\right) F^{2}-\left(b_{5} X_{c}+b_{6}\right) F-b_{7} X_{c}=0 \\
& X_{c}=\frac{b_{1} F^{4}-b_{2} F^{3}-b_{4} F^{2}+b_{6} F}{b_{3} F^{2}-b_{5} F-b_{7}}
\end{aligned}
$$

The Constants from al to a5 as well as b1 to b7 are calculated as shown in Appendix 1. The following equation is resulted from (9) and (12). 


$$
\frac{a_{1} F^{3}-a_{2} F^{2}-a_{4} F}{a_{3} F-a_{5}}=\frac{b_{1} F^{4}-b_{2} F^{3}-b_{4} F^{2}+b_{6} F}{b_{3} F^{2}-b_{5} F-b_{7}}
$$

After a tedious elaboration, (13) can be reduced to the 4th order equation:

$$
C_{0} F^{4}+C_{1} F^{3}+C_{2} F^{2}+C_{3} F+C_{4}=0
$$

The Coefficients $\mathrm{Cn}, \mathrm{n}=0,1,2$, 3and 4 are given in Appendix I. it is clear that these coefficients do not involve $\mathrm{X}_{\mathrm{C}}$. Solving (14) helps effectively in calculating the operating frequency. The solution of (14) has four roots (two real and two imaginary); largest positive real root gives the minimum capacitance Cmin [21-23].

Moreover, smaller real root gives the maximum capacitance. The absence of positive real root means there is no self-excitation. Value of operating frequency it can be put in (9) or (12) in order to evaluate Xc. Finally the capacitance Without Iron Losses is obtained as follows:

$$
C_{\min }=\frac{1}{2 \pi}\left[\frac{X_{m o t} * F}{Z_{3}}+\frac{Z_{4}}{Z_{1}^{2}+Z_{2}^{2}}\right]
$$

The capacitance With Iron Losses is obtained as follows:

$$
C_{\text {min-new }}=\frac{1}{2 \pi}\left[\frac{X_{m o t} * F}{W_{3}}+\frac{W_{4}}{W_{1}^{2}+W_{2}^{2}}\right]
$$

The coefficients Z1, Z2, Z3 and Z4 of (15) and coefficients W1, W2, W4 and W4 are shown in Appendix I. in short, the excitation capacitance is measured by using any program computer.

\section{THE CHARACTERISTICS OF SEIG WITH IRON LOSSES (REG)}

The accuracy of the machine's parameters represents one of the main design factors. Using induction generator as motor, during conducting tests, helps effectively in calculating the parameters of SEIG. In clear, the main two tests are open and short circuit tests. The parameters which are calculated from these tests are $\mathrm{Ls}=\mathrm{Lr}=10.286 \mathrm{mH}, \mathrm{Lm}=252.5 \mathrm{mH}, \mathrm{RC}=603.3 \Omega, \mathrm{Rs}=2.37 \Omega, \mathrm{Rr}=1.53 \Omega$. These tests had been performed at rated values of voltage and frequency. Moreover, this data is useful for wide motoring applications. However, the deviation of voltage with $\mathrm{Lm}$ and $\mathrm{R}_{\mathrm{eG}}$ represents one of the factors should be taken into consideration in SEIG applications.

The accuracy of the parameters such as the output power, induced electromagnetic torque, and dynamic currents support largely in design applications. To calculate magnetizing inductance practically, induction machine has to be operated at synchronous speed and it is measured when applied voltage starts varying. Figure 3 demonstrates the connection between saturated inductance $(\mathrm{Lm})$ with phase voltage.

Saturated inductance $(\mathrm{Lm})$ increases gradually from lower value at the beginning and continues increasing up to maximum value then decreases at the end. This property of Lm is useful for the voltage stability as well as in determining the smallest generated voltage during self-excitation. The variation of RC increases with increasing generated voltage. Moreover, neglecting RC increases analysis error especially during the equality between the per-unit value of $\mathrm{RC}$ and $\mathrm{Xm}$. Moreover, polynomial equation below shows magnetizing inductance $(\mathrm{Lm})$ with phase voltage at $50 \mathrm{~Hz}[24,25]$.

$$
\begin{aligned}
& \mathrm{Lm}=2 \mathrm{E}-13 \mathrm{~V}^{6}-1 \mathrm{E}-10 \mathrm{~V}^{5}+5 \mathrm{E}-08 \mathrm{~V}^{4}-7 \mathrm{E}-06 \mathrm{~V}^{3}+0.0004 \mathrm{~V}^{2}-0.0058 \mathrm{~V}+0.2266 \\
& \mathrm{Lm}=-0.0783 \mathrm{Im}^{6}+0.8477 \mathrm{Im}^{5}-3.6608 \mathrm{Im}^{4}+8.0005 \mathrm{Im}^{3}-9.1999 \mathrm{Im}^{2}+5.0953 \mathrm{Im}-0.6177
\end{aligned}
$$

The interpretation of the curve in Figure 3 as follows. Between point $\mathrm{O}$ and $\mathrm{N}$ is the unstable area. If the self-induction generator (SEIG) starts in this area, a slight decrease in speed will lead to a decrease in voltage and this will lead to a decrease in Lm, which in turn leads to a decrease in voltage and eventually the voltage will collapse to zero. If the speed increases slowly and sometimes without zero acceleration so that the operating point remains in the area between $\mathrm{O}$ and $\mathrm{N}$, there will be no self- excitation even at high speed. When wind speed increases with this characteristic, there is the possibility that there will be no self- excitation.

For the purpose of solving this problem, the capacitors must be connected when the speed reaches the set-point. This is because the built-up of the voltages requires passage in the transient state of the specified area between $\mathrm{O}$ and $\mathrm{N}$. While the area between points $\mathrm{N}$ and $\mathrm{P}$ represents the stable operating 
area.but when the speed is decrease leads to decrease voltages also, while there is an increase in the value of the inductance $(\mathrm{Lm})$, this leads to have a new steady state operating point at lower voltage. The magnetizing inductance with magnetizing current at $50 \mathrm{~Hz}$ and the polynomial equation used in this investigation in Figure 4.

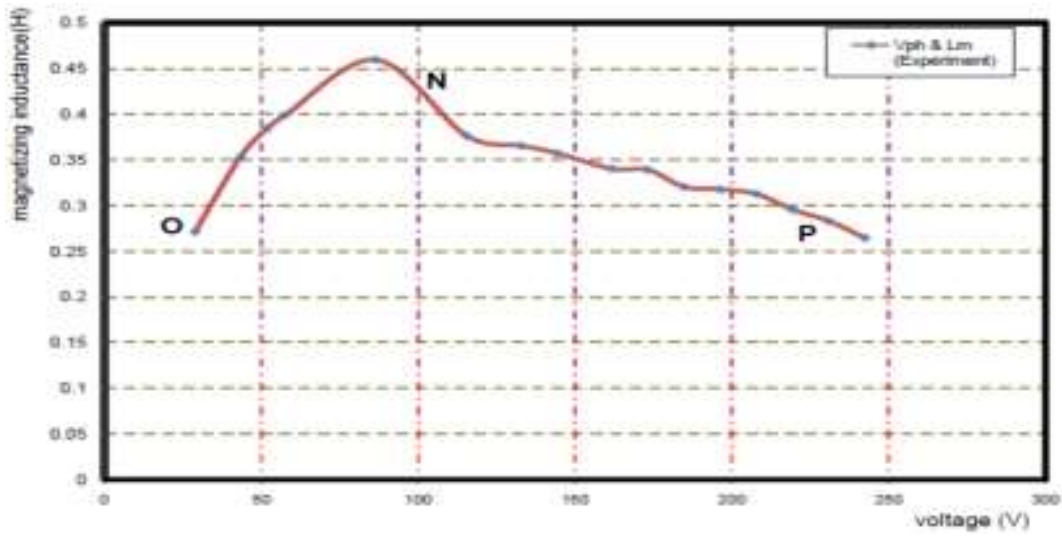

Figure 3. Variation of magnetising inductance with phase voltage at $50 \mathrm{~Hz}$

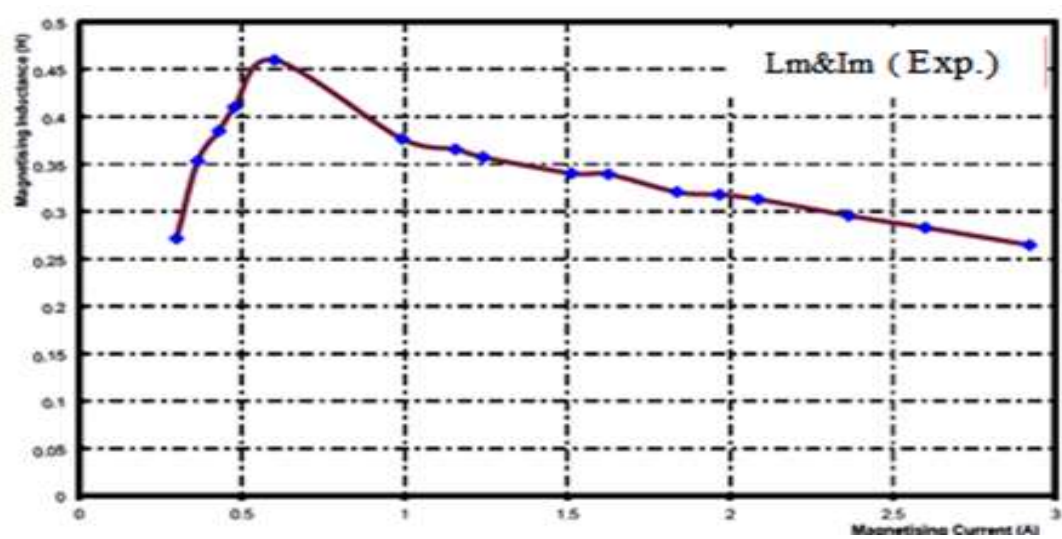

Figure 4. Lm as a function of the magnetizing current

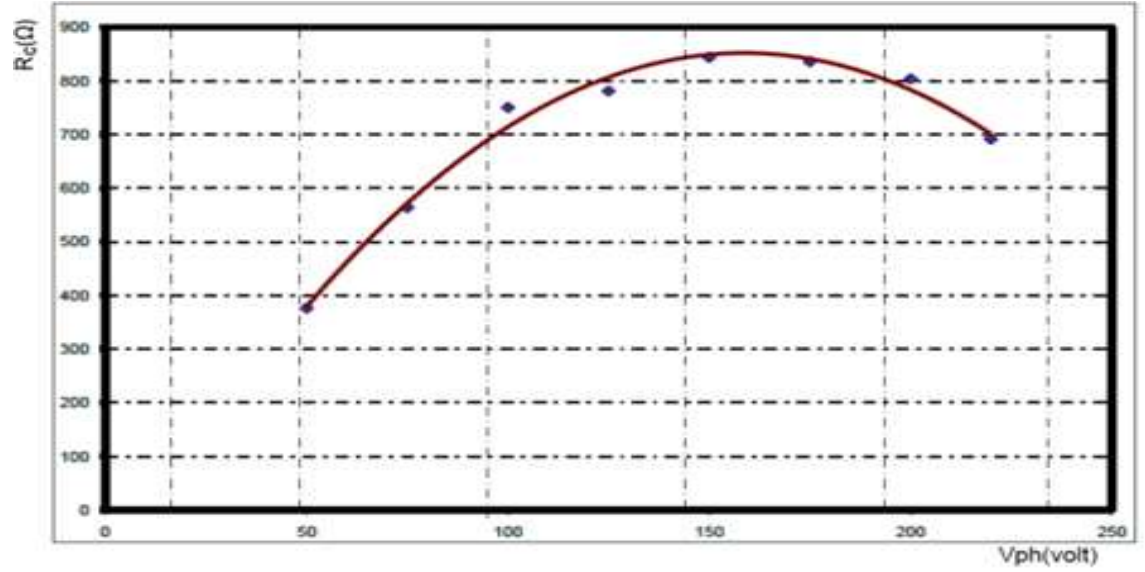

Figure 5. Variation of $\mathrm{R}_{\mathrm{eG}}$ with phase voltage

The variation of $R_{e G}$ with phase voltage is shown in Figure 5. Grantham [9] was reported the value of $R_{e G}$ for IM. The variation in the $\mathrm{R}_{\mathrm{eG}}$ is formulated according to the following curve. 


$$
R_{e G}=-0.04 V_{p h}^{2}+12.72 V_{p h}
$$

Where,

Vph: rms phase voltage across RC. Vph for generator can be estimated by summation the voltage across the impedance of the machine stator and voltage appearance on the terminals of its.

$\mathrm{Kd}$ and $\mathrm{Kq}$ in (21) considered the initial induced voltages along the d-axis and q-axis respectively due to the residual magnetic flow in the core, the primary voltages (Vcqo and Vcdo) are on the capacitors.

$$
\begin{aligned}
& {\left[\begin{array}{l}
0 \\
0 \\
0 \\
0
\end{array}\right]=}
\end{aligned}
$$

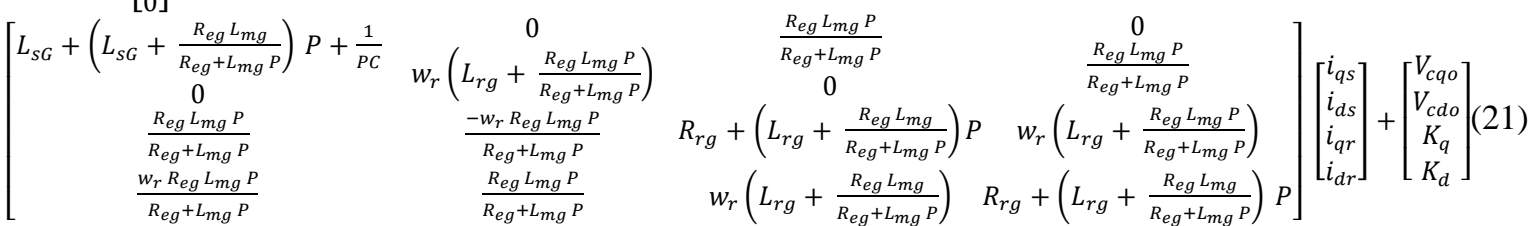

The residual magnetic remnants in the rotor and charge due to from capacitance initial value are not take in the considered because they will be cancelled from two sides of (21) these initial values can be obtain from derivation this equation [9].

\section{APPLICATIONS AND RESULTS}

The results using these technique must be close to $(15,16$, and 17) Table 1 shows the results obtained using these method. Figure $6(\mathrm{a}, \mathrm{b})$ minimum capacitance with load reactance at different speeds (28rpm, 56rpm, 84rpm and 112rpm) (a- without iron losses b-With iron losses). It is seen that the capacitance increases rapidly with increases in load reactance and then decrease. Also It is seen the induction generator fails to excite irrespective of the value of excitation capacitance at speeds (28rpm and 56rpm).

\begin{tabular}{|c|c|c|c|c|c|c|}
\hline \multirow[b]{2}{*}{$\begin{array}{l}\text { Speed } \\
\text { (pu) }\end{array}$} & \multicolumn{3}{|c|}{ Without Iron Losses } & & \multicolumn{2}{|c|}{ With Iron Losses } \\
\hline & Ro & & $\begin{array}{c}\text { Capacitance } \\
(\mu \mathrm{F})\end{array}$ & & Roots & $\begin{array}{c}\text { Capacitance } \\
(\mu \mathrm{F})\end{array}$ \\
\hline 1 & 0.9997 & 0.6194 & 47.6249 & 0.9995 & 0.6219 & 52.5269 \\
\hline & $0.0002+0.0491 \mathrm{i}$ & $0.0002-0.0491 \mathrm{i}$ & & $0.0002+0.049$ & $0.0002-0.0491 \mathrm{i}$ & \\
\hline 0.9 & $\begin{array}{l}0.0823+0.9938 \mathrm{i} \\
0.8854\end{array}$ & $\begin{array}{l}0.0823-0.9938 \mathrm{i} \\
0.5910\end{array}$ & 106.3582 & $\begin{array}{c}0.0822+0.9940 \mathrm{i} \\
0.8818\end{array}$ & $\begin{array}{c}0.0822-0.9940 \mathrm{i} \\
0.5954\end{array}$ & 113.4791 \\
\hline 0.8 & $\begin{array}{l}0.0744+0.9507 \mathrm{i} \\
0.7859\end{array}$ & $\begin{array}{l}0.0744-0.9507 \mathrm{i} \\
0.5181\end{array}$ & 114.3463 & $\begin{array}{c}0.0719+0.9341 \mathrm{i} \\
0.7826\end{array}$ & $\begin{array}{c}0.0719-0.9341 \mathrm{i} \\
0.5219\end{array}$ & 123.7555 \\
\hline 0.7 & $\begin{array}{c}0.0746+0.9610 \mathrm{i} \\
0.6858\end{array}$ & $\begin{array}{c}0.0746-0.9610 \mathrm{i} \\
0.4471\end{array}$ & 117.6768 & $\begin{array}{c}0.0728+0.9471 \mathrm{i} \\
0.6824\end{array}$ & $\begin{array}{c}0.0728-0.9471 \mathrm{i} \\
0.4508\end{array}$ & 128.3868 \\
\hline 0.6 & $\begin{array}{c}0.0727+0.9685 \mathrm{i} \\
0.5862\end{array}$ & $\begin{array}{c}0.0727-0.9685 \mathrm{i} \\
0.3776\end{array}$ & 120.0382 & $\begin{array}{c}0.0712+0.9557 \mathrm{i} \\
0.5828\end{array}$ & $\begin{array}{c}0.0712-0.9557 \mathrm{i} \\
0.3809\end{array}$ & 132.4273 \\
\hline 0.5 & $\begin{array}{c}0.0687+0.9774 \mathrm{i} \\
0.4869\end{array}$ & $\begin{array}{c}0.0687-0.9774 \mathrm{i} \\
0.3098\end{array}$ & 121.1769 & $\begin{array}{c}0.0678+0.9665 \mathrm{i} \\
0.4836\end{array}$ & $\begin{array}{c}0.0678-0.9665 \mathrm{i} \\
0.3127\end{array}$ & 135.6226 \\
\hline 0.4 & $\begin{array}{l}0.0621+0.9851 \mathrm{i} \\
0.3882\end{array}$ & $\begin{array}{l}0.0621-0.9851 \mathrm{i} \\
0.2440\end{array}$ & 122.6575 & $\begin{array}{c}0.0616+0.9768 \mathrm{i} \\
0.3852\end{array}$ & $\begin{array}{c}0.0616-0.9768 \mathrm{i} \\
0.2464\end{array}$ & 139.7903 \\
\hline 0.3 & $\begin{array}{l}0.0524+0.9899 \mathrm{i} \\
0.2900\end{array}$ & $\begin{array}{l}0.0524-0.9899 \mathrm{i} \\
0.1803\end{array}$ & 128.6802 & $\begin{array}{c}0.0523+0.9849 \mathrm{i} \\
0.2873\end{array}$ & $\begin{array}{c}0.0523-0.9849 \mathrm{i} \\
0.1823\end{array}$ & 150.4189 \\
\hline 0.2 & $\begin{array}{c}0.0389+0.9880 \mathrm{i} \\
0.1922\end{array}$ & $\begin{array}{c}0.0389-0.9880 \mathrm{i} \\
0.1188\end{array}$ & 152.6214 & $\begin{array}{c}0.0390+0.9859 \mathrm{i} \\
0.1900\end{array}$ & $\begin{array}{c}0.0390-0.9859 \mathrm{i} \\
0.1205\end{array}$ & 184.2516 \\
\hline 0.1 & $\begin{array}{c}0.0214+0.9748 \mathrm{i} \\
0.0944\end{array}$ & $\begin{array}{c}0.0214-0.9748 \mathrm{i} \\
0.0598\end{array}$ & 259.6760 & $\begin{array}{c}0.0215+0.9749 \mathrm{i} \\
0.0924\end{array}$ & $\begin{array}{c}0.0215-0.9749 \mathrm{i} \\
0.0615\end{array}$ & 325.0065 \\
\hline 0.09 & $\begin{array}{c}0.0096+0.4940 \mathrm{i} \\
0.0839\end{array}$ & $\begin{array}{c}0.0096-0.4940 \mathrm{i} \\
0.0531\end{array}$ & 389.3625 & $\begin{array}{c}0.0098+0.4889 \mathrm{i} \\
0.0816\end{array}$ & $\begin{array}{c}0.0098-0.4889 \mathrm{i} \\
0.0549\end{array}$ & 467.0672 \\
\hline 0.08 & $\begin{array}{c}0.0093+0.5302 \mathrm{i} \\
0.0741\end{array}$ & $\begin{array}{c}0.0093-0.5302 \mathrm{i} \\
0.0476\end{array}$ & 404.2504 & $\begin{array}{c}0.0095+0.5279 \mathrm{i} \\
0.0717\end{array}$ & $\begin{array}{c}0.0095-0.5279 \mathrm{i} \\
0.0495\end{array}$ & 491.4755 \\
\hline 0.07 & $\begin{array}{c}0.0089+0.5735 \mathrm{i} \\
0.0642\end{array}$ & $\begin{array}{c}0.0089-0.5735 \mathrm{i} \\
0.0422\end{array}$ & 430.6683 & $\begin{array}{c}0.0091+0.5724 \mathrm{i} \\
0.0616\end{array}$ & $\begin{array}{c}0.0091-0.5724 \mathrm{i} \\
0.0444\end{array}$ & 531.1832 \\
\hline 0.06 & $\begin{array}{c}0.0085+0.6211 \mathrm{i} \\
0.054\end{array}$ & $\begin{array}{l}0.0085-0.6211 \mathrm{i} \\
0.0371\end{array}$ & 476.4450 & $\begin{array}{c}0.0087+0.6220 \mathrm{i} \\
0.0510\end{array}$ & $\begin{array}{c}0.0087-0.6220 \mathrm{i} \\
0.0399\end{array}$ & 594.8757 \\
\hline 0.05 & $\begin{array}{l}0.0079+0.6724 \mathrm{i} \\
0.0437\end{array}$ & $\begin{array}{r}0.0079-0.6724 \mathrm{i} \\
0.0323\end{array}$ & 550.8193 & $\begin{array}{l}0.0081+0.6779 \mathrm{i} \\
0.0378+0.0024 \mathrm{i}\end{array}$ & $\begin{array}{l}0.0081-0.6779 \mathrm{i} \\
0.0378-0.0024 \mathrm{i}\end{array}$ & No excitation \\
\hline 0.04 & $\begin{array}{l}0.0070+0.7272 \mathrm{i} \\
0.0304+0.0006 \mathrm{i}\end{array}$ & $\begin{array}{l}0.0070-0.7272 \mathrm{i} \\
0.0304-0.0006 \mathrm{i}\end{array}$ & No excitation & $\begin{array}{l}0.0065+0.6781 \mathrm{i} \\
0.0303+0.0060 \mathrm{i}\end{array}$ & $\begin{array}{l}0.0065-0.6781 \mathrm{i} \\
0.0303-0.0060 \mathrm{i}\end{array}$ & No excitation \\
\hline
\end{tabular}

Table 1. Frequency \&Speed Variation at base speed is $1400 \mathrm{rpm}$ 


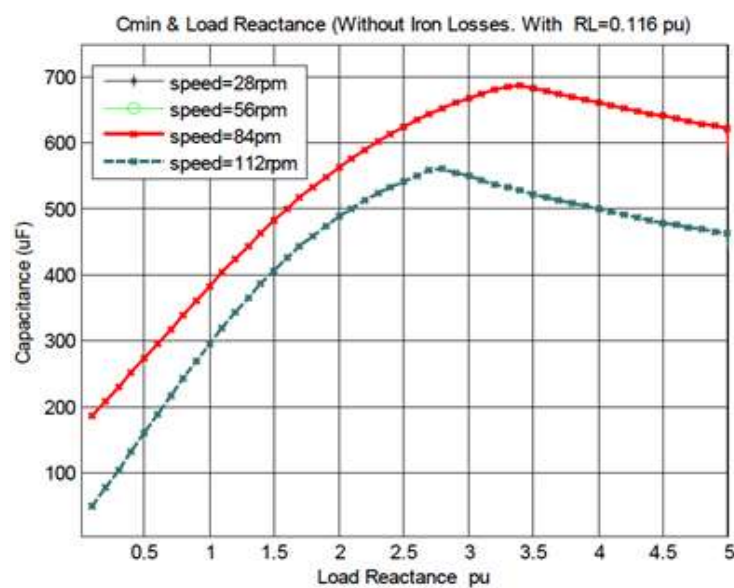

(a)

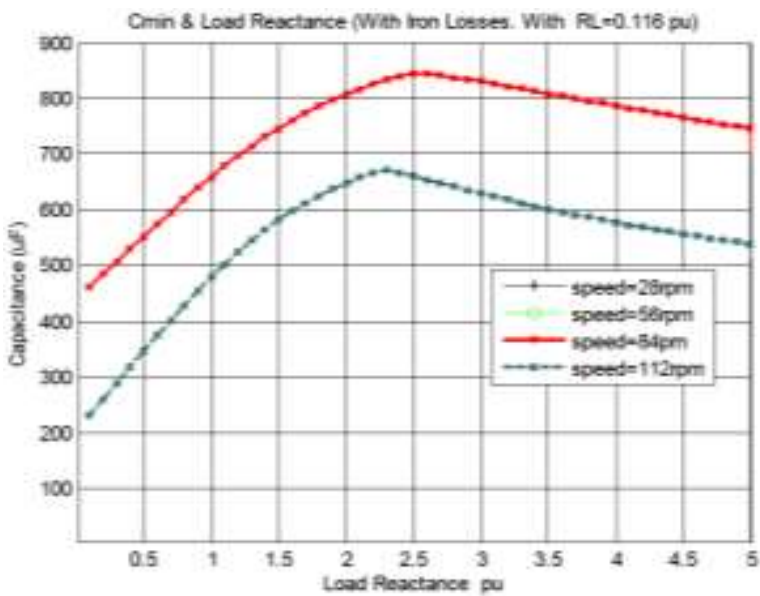

(b)

Figure 6. (a) $\mathrm{C}_{\min }$ and load reactance ( $\mathrm{RL}=0.116 \mathrm{pu}$ ) with different speed, (b) $\mathrm{C}_{\min }$ and load reactance $(\mathrm{RL}=0.116 \mathrm{pu})$ with different speed

Figure $7(a, b)$ shows the variation minimum capacitance with load Resistance at different speeds (28rpm, 56rpm, 84rpm and 112rpm) (a- without iron losses b-With iron losses). It is seen that the capacitance decrease rapidly with increases in load Resistance. also It is seen the induction generator fails to excite irrespective of the value of excitation capacitance at speeds (28rpm and 56rpm without iron losses). While with iron losses there will not be any excitation Below the speed 112rpm.

Figure $8(\mathrm{a}, \mathrm{b})$ minimum capacitance with load reactance at different speeds (70rpm, 140rpm, $210 \mathrm{rpm}$ and 280rpm) (a- without iron losses b-With iron losses). It is seen no exaction with iron losses at speeds 70rpm while the exaction occur when iron losses neglected at the same speed .

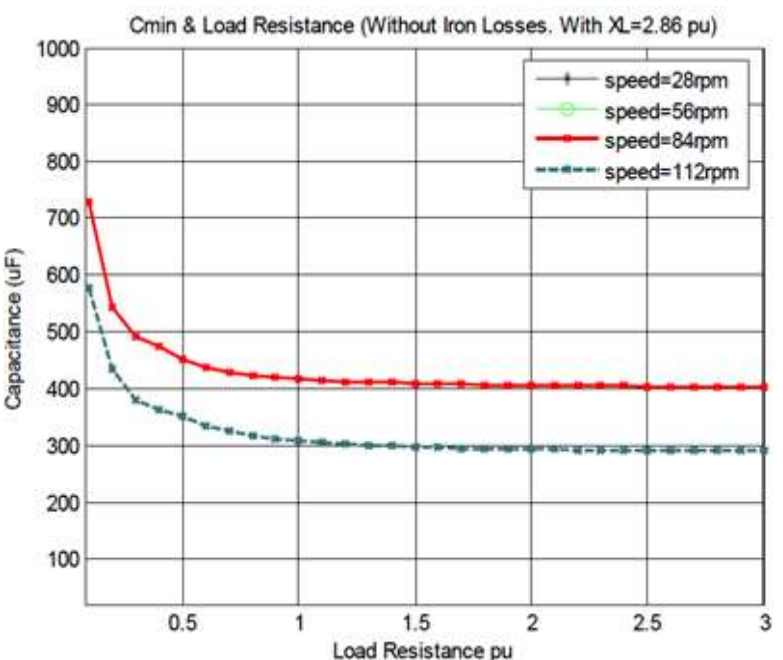

(a)

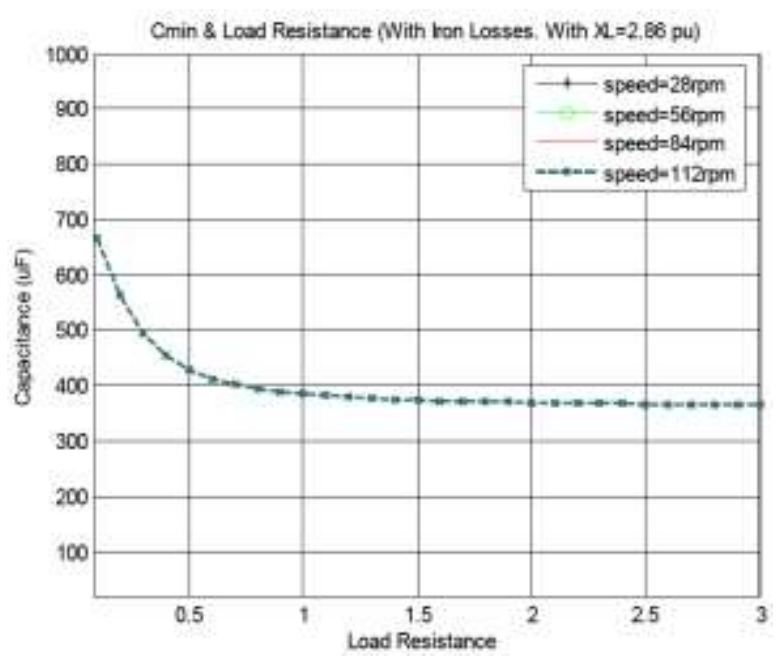

(b)

Figure 7. (a) $\mathrm{C}_{\min }$ and load resistance $(\mathrm{XL}=2.86 \mathrm{pu})(28-112) \mathrm{rpm}$, (b) $\mathrm{C}_{\min }$ and load resistance (XL=2.86pu) (28-112)rpm

Figure $9(\mathrm{a}, \mathrm{b})$ relation between minimum capacitance with load reactance at different speeds It is observed the value of minimum_capacitance at minimum speed(140 rpm ) is much smaller than the value at higher speed. Also, It is observed minimum capacitance with iron losses is higher than without iron losses at the same load reactance $(0.1 \mathrm{pu})$ and speed $(140 \mathrm{rpm})$. We see from both cases in the figures the minimum excitation capacitance value with iron loss is strongly influenced when the speed decreased. 
Figure $10(\mathrm{a}, \mathrm{b})$ observe the difference values of capacitance required with load resistance when the Load reactance 2.86pu varies for different values of rotor speed. It is noted that increasing in load Resistance requires decreasing capacitance value. Also It is observed that actual value of minimum exaction capacitance for the given when iron losses neglected which is much smaller than the value obtained with iron losses included.

By comparing the results obtained after taking into consideration the effect of iron losses observed in the Table 1, and without consideration in [10-13]. They have ignored the iron losses in calculating the minimum capacitance, this is because they consider the effect is small. But in this paper, we demonstrate that the influence of iron losses is little only at a rated speed of generators. While at low wind speeds, this effect becomes high. This is meaning the influence of iron losses on determining minimum capacitance increases gradually with wind speed decreases.

Figure 11 shows the percentage difference of minimum excitation capacitance obtained with and without a core-loss resistance varies with different values of speed (Load- Induction Pump Motor). The average difference of capacitance reaches to $13.48 \%$.

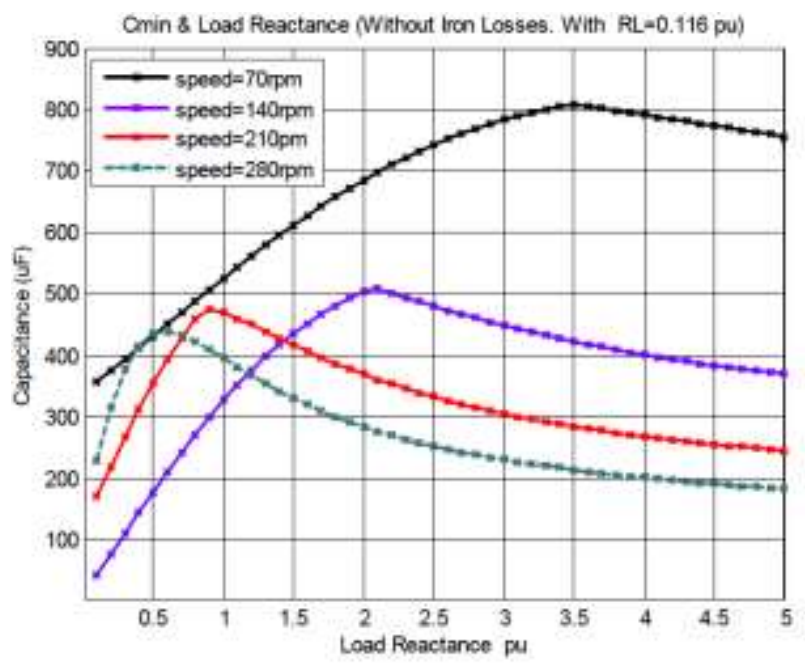

(a)

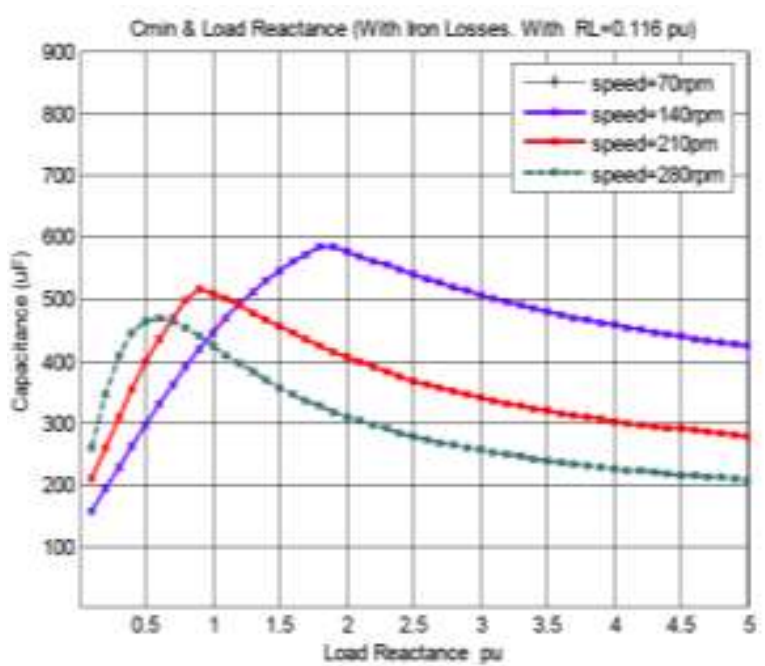

(b)

Figure 8. (a) $\mathrm{C}_{\min }$ and load reactance (70-280)rpm, (b). $\mathrm{C}_{\min }$ and load reactance (70-280)rpm

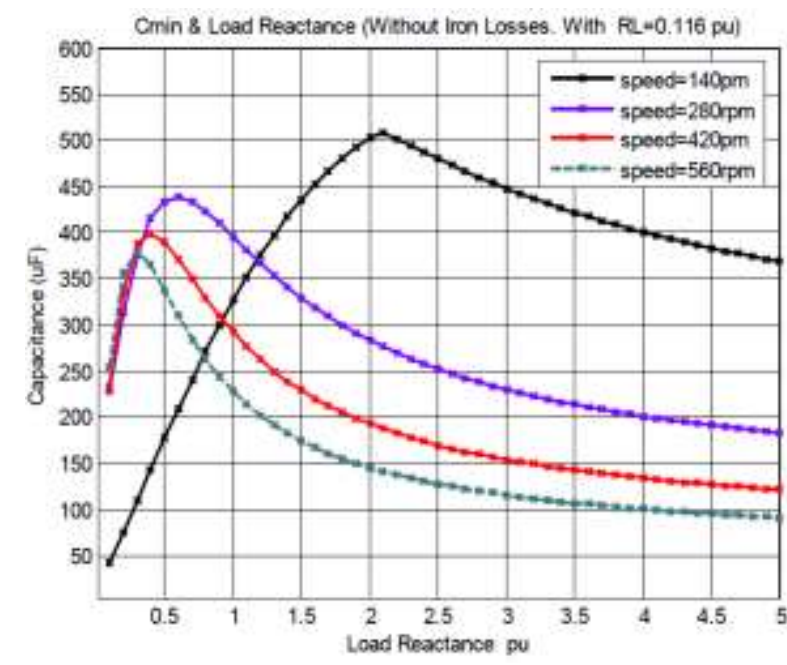

(a)

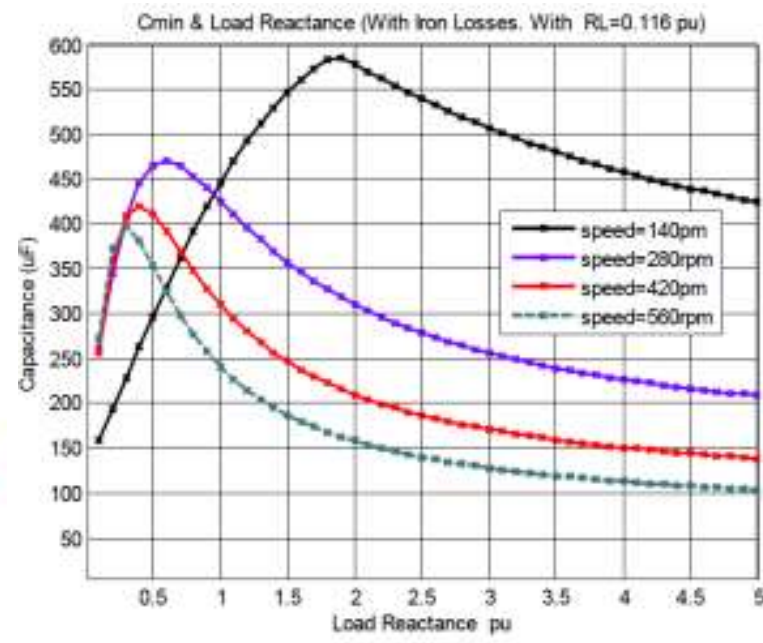

(b)

Figure 9. (a) $\mathrm{C}_{\min }$ and load reactance $(\mathrm{RL}=0.116 \mathrm{pu})$, (b). $\mathrm{C}_{\min }$ and load reactance( $\left.\mathrm{RL}=0.116 \mathrm{pu}\right)$ 


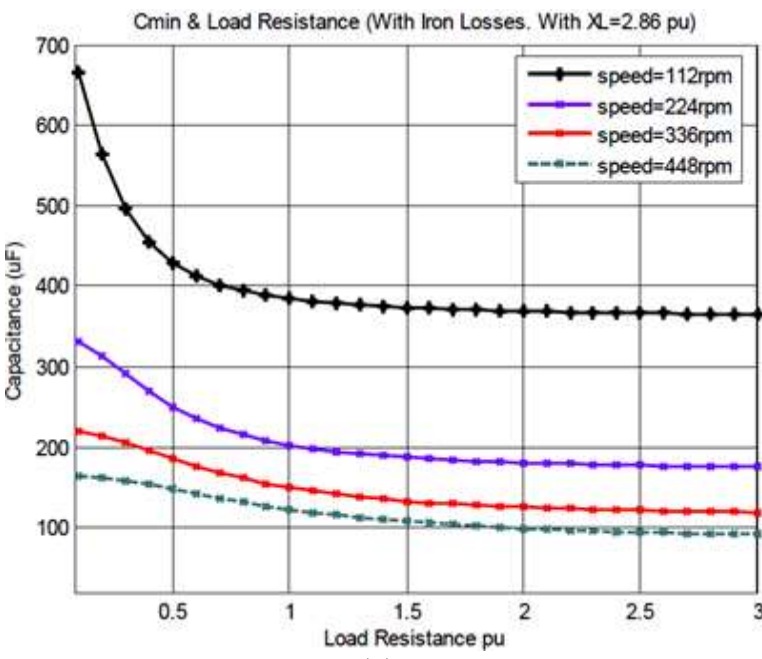

(a)

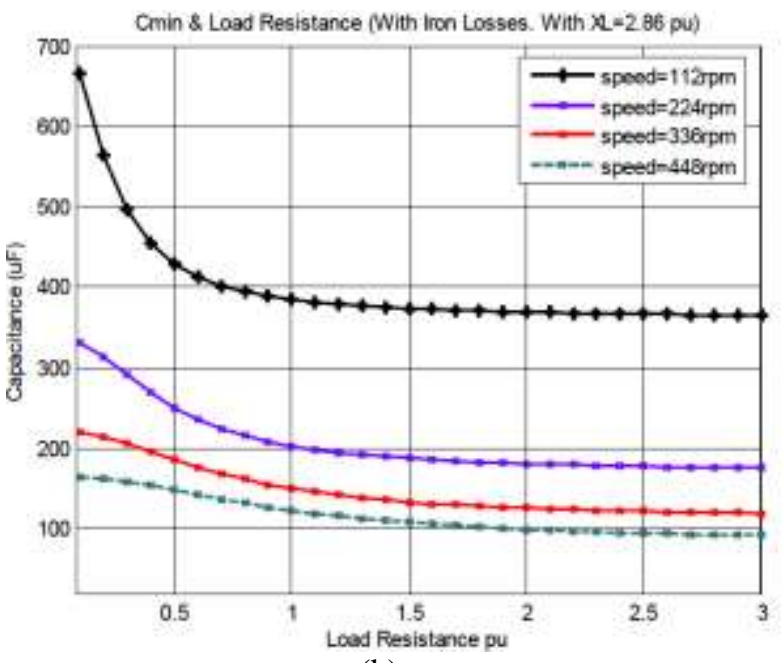

(b)

Figure 10. (a) $\mathrm{C}_{\min }$ and load resistance $(\mathrm{XL}=2.86 \mathrm{pu})(112-448) \mathrm{rpm},(\mathrm{b}), \mathrm{C}_{\min }$ and load resistance $(\mathrm{XL}=2.86 \mathrm{pu})$ (112-448)rpm

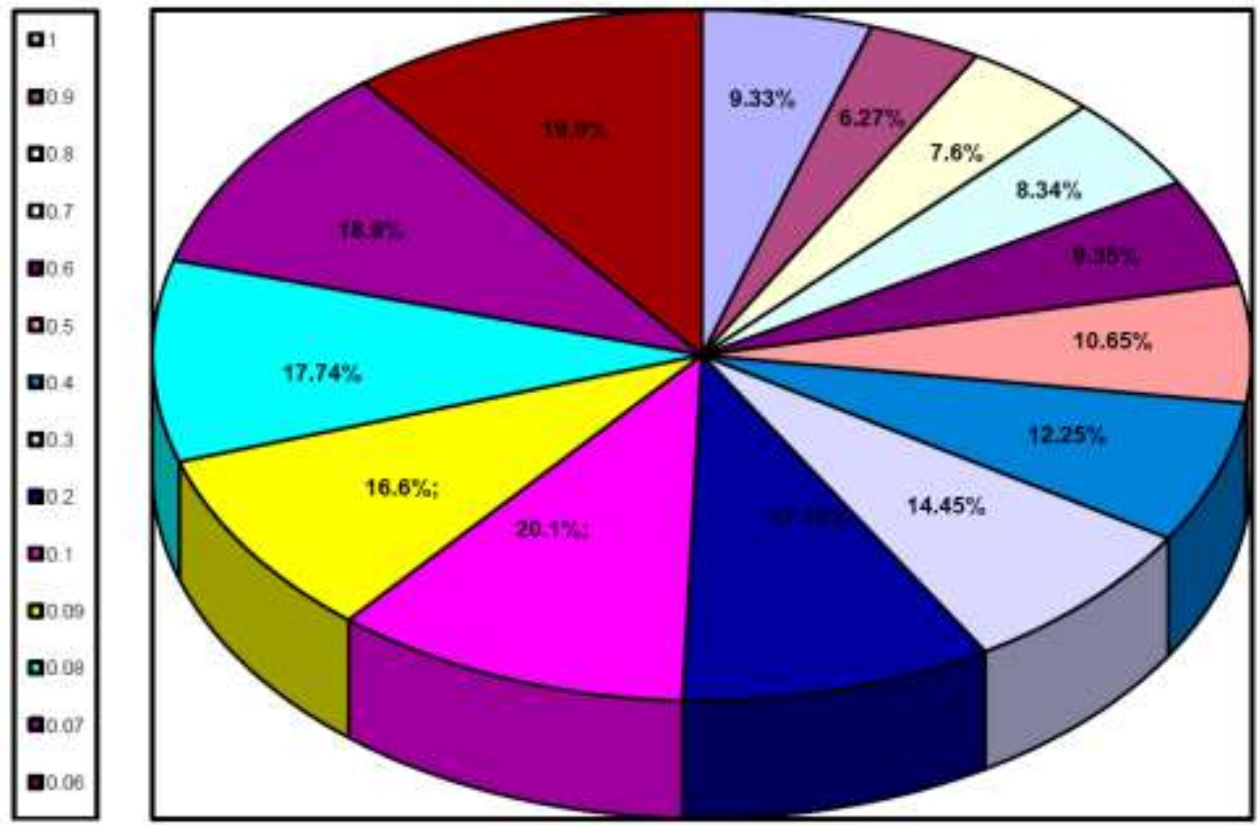

Figure 11. Minimum excitation capacitance with Induction Pump Motor(load)With different speed

\section{CONCLUSION}

Self excitation in induction machine depends on machine parameters like speed, load and excitation capacitance. If the suitable value of capacitance is selected, the generator will operate in self-excited mode. This paper has described influence the core loss resistance on the choice of minimum excitation capacitance required (Cmin), this effect is mentioned in the different of an excitation capacitor on the steady state behavior of the SEIG. The presented comparisons between the calculated capacitance with the core loss resistance and them without it prove consistent effect of this parameter on the accuracy of the determined results. The degradation of the accuracy performances due to the neglected core loss resistance leads, revilement, to false results and a bed interpretation and consequently ironed contribution for the drawbacks of the studied minimum excitation capacitance for self excited induction generator. 


\section{APPENDIX}

Table 2. Induction motor parameters

\begin{tabular}{cc}
\hline \multicolumn{2}{c}{ Rated Power $1.5 \mathrm{kw}$} \\
\hline Voltage & $380 \mathrm{~V}-\mathrm{Y}$ \\
Frequency & $50 \mathrm{~Hz}$ \\
Pair Pole & 2 \\
Rated Speed & $1440 \mathrm{rpm}$ \\
Stator Resistance & $4.85 \Omega$ \\
Rotor Resistance & $3.805 \Omega$ \\
Stator Inductance & $274 \mathrm{mH}$ \\
Rotor Inductance & $274 \mathrm{mH}$ \\
Mutual Inductance & $258 \mathrm{mH}$ \\
Moment of Inertia & $0.031 \mathrm{Kg} . \mathrm{m} 2$ \\
\hline
\end{tabular}

Table 3. Induction Generator Parameters

\begin{tabular}{|c|c|}
\hline Rated Power $3 \mathrm{kw}$ & \\
\hline Voltage & $420 \mathrm{~V}-\mathrm{Y}$ \\
\hline Frequency & $50 \mathrm{~Hz}$ \\
\hline Pair Pole & 2 \\
\hline Rated Speed & $1420 \mathrm{rpm}$ \\
\hline Stator Resistance & $2.37 \Omega$ \\
\hline Rotor Resistance & $1.53 \Omega$ \\
\hline Stator Inductance & $10.28 \mathrm{mH}$ \\
\hline Rotor Inductance & $10.28 \mathrm{mH}$ \\
\hline Mutual Inductance & $252.32 \mathrm{mH}$ \\
\hline Core loss & 603.3 \\
\hline
\end{tabular}

$\mathrm{A} 1=-[\mathrm{R} \operatorname{mot}(\mathrm{Xrg}+\mathrm{Xsg})+\mathrm{X} \operatorname{mot}(\mathrm{Rrg}+\mathrm{Rsg})]$,

$\mathrm{A} 3=\mathrm{v}[\mathrm{R} \operatorname{mot}(\mathrm{Xsg}+\mathrm{Xrg})+\mathrm{Rsg} \mathrm{X} \operatorname{mot}]$,

$\mathrm{A} 5=\mathrm{Xc}(\mathrm{Rrg}+\mathrm{R}$ mot $+\mathrm{Rsg})$,

$\mathrm{A} 7=-\mathrm{v} X \mathrm{C}(\mathrm{R}$ mot $+\mathrm{Rsg})$,
$\mathrm{A} 2=-[\operatorname{Rsg} \mathrm{X}$ mot $\mathrm{Xrg}+\mathrm{Rrg} \mathrm{X}$ mot $\mathrm{Xsg}+\mathrm{R}$ mot Xsg Xrg]

$\mathrm{A} 4=\mathrm{v}[\mathrm{Xrg}(\operatorname{Rsg} \mathrm{X}$ mot $+\mathrm{R} \operatorname{mot} \mathrm{Xsg})]$

$\mathrm{A} 6=\mathrm{Xc} \mathrm{Xrg}(\mathrm{R}$ mot $+\mathrm{Rsg})+\mathrm{Xc} \operatorname{Rrg}(\mathrm{X}$ mot $+\mathrm{Xsg})$

$\mathrm{A} 8=-\mathrm{v}$ Xc Xrg $(\mathrm{R}$ mot $+\mathrm{Rsg})$

$\mathrm{a} 1=\mathrm{X}$ mot $[\mathrm{Rrg}(\mathrm{Xmg}+\mathrm{Xsg})+\mathrm{Rsg}(\mathrm{Xmg}+\mathrm{Xrg})]+\mathrm{R} \operatorname{mot}(\mathrm{Xmg}+\mathrm{Xrg})[\mathrm{Xsg}+(\mathrm{Xrg} \mathrm{Xmg} / \mathrm{Xmg}+\mathrm{Xrg})]$

$\mathrm{a} 2=\mathrm{v}(\mathrm{Xmg}+\mathrm{Xrg})+[\mathrm{R} \operatorname{mot}(\mathrm{Xsg}+(\mathrm{Xrg} \mathrm{Xmg} / \mathrm{Xmg}+\mathrm{Xrg})+\mathrm{Rsg} \mathrm{X}$ mot $]$

$\mathrm{a} 3=\operatorname{Rrg}(\mathrm{Xmg}+\mathrm{Xrg}+\mathrm{Xsg})+\mathrm{R} \operatorname{mot}(\mathrm{Xmg}+\mathrm{Xrg})+\operatorname{Rsg}(\mathrm{Xrg}+\mathrm{Xmg})$

a4=Rsg Rrg R mot,

b1=X mot (Xrg Xmg+Xsg Xmg +Xrg Xsg),

$\mathrm{b} 3=(\mathrm{Xrg}+\mathrm{Xmg})(\mathrm{Xrg}+\mathrm{Xsg})+\mathrm{Xrg} \mathrm{Xmg}$,

$\mathrm{b} 5=\mathrm{v}[(\mathrm{Xrg}+\mathrm{Xmg})(\mathrm{Xrg}+\mathrm{Xsg})+\mathrm{Xrg} \mathrm{Xmg}]$,

$\mathrm{b} 7=\operatorname{Rrg}(\mathrm{R}$ mot $+\mathrm{Rsg})$

\section{Without Iron Losses}

$\mathrm{R}_{\mathrm{mot}}=\mathrm{R}_{\mathrm{rm}}+\frac{\mathrm{F}(\mathrm{F}-\mathrm{V}) \mathrm{X}_{\mathrm{MM}}^{2} \mathrm{R}_{\mathrm{rm}}}{\mathrm{R}_{\mathrm{rm}}^{2}+\left(\mathrm{X}_{\mathrm{rm}}+\mathrm{X}_{\mathrm{MM}}\right)^{2}+(\mathrm{F}-\mathrm{V})^{2}}$

$X_{\text {mot }}=F X_{s m}+\frac{F X_{s m}\left((F-V)^{2} X_{r m}\left(X_{M M}+X_{r m}\right)+R_{r m}^{2}\right.}{R_{r m}^{2}+\left(X_{r m}+X_{M M}\right)^{2}+(F-V)^{2}}$

$\begin{array}{lll}\mathrm{L} 1=\mathrm{X}_{\mathrm{sg}} *\left(\mathrm{X}_{\mathrm{rg}}+\mathrm{X}_{\mathrm{mg}}\right)+\mathrm{X}_{\mathrm{rg}} * \mathrm{X}_{\mathrm{mg}}, & \mathrm{L} 2=\mathrm{X}_{\mathrm{rg}}+\mathrm{X}_{\mathrm{mg}}, & \mathrm{L} 3=\mathrm{X}_{\mathrm{sg}}+\mathrm{X}_{\mathrm{mg}} \\ \mathrm{C}_{\mathrm{O}}=\left(\mathrm{R}_{\mathrm{rg}}^{2}+\mathrm{L}^{2}{ }_{2} * \mathrm{v}^{2}\right) * \mathrm{R}_{\mathrm{mot}} * \mathrm{R}_{\mathrm{sg}} *\left(\mathrm{R}_{\mathrm{mot}}+\mathrm{R}_{\mathrm{sg}}\right), & \mathrm{C}_{1}=\mathrm{R}_{\mathrm{mot}}^{2} * \mathrm{R}_{\mathrm{rg}} * \mathrm{v} *\left(\mathrm{~L}_{1}-\mathrm{L}_{2} * \mathrm{~L}_{3}\right)-2 * \mathrm{v}^{*} \mathrm{R}_{\mathrm{mot}} * \mathrm{R}_{\mathrm{sg}} \mathrm{L}_{2}{ }_{2}\left(\mathrm{R}_{\mathrm{sg}}+\right.\end{array}$

$\mathrm{R}_{\text {mot }}$ )

$\mathrm{C}_{2}=\mathrm{R}^{2}{ }_{\text {mot }}\left(\mathrm{R}_{\mathrm{rg}} \mathrm{L}^{2}{ }_{2}-\mathrm{R}_{\mathrm{rg}} \mathrm{L}_{1}+\mathrm{R}_{\mathrm{rg}} \mathrm{L}_{2} \mathrm{~L}_{3}+\mathrm{X}^{2}{ }_{\mathrm{mot}} \mathrm{R}_{\mathrm{sg}}\left(\mathrm{R}_{\mathrm{rg}}^{2}+\mathrm{L}^{2}{ }_{2} \mathrm{v}^{2}\right)+2 * \mathrm{R}_{\mathrm{mot}} \mathrm{R}_{\mathrm{rg}} \mathrm{R}_{\mathrm{sg}}\left(\mathrm{L}_{2} \mathrm{~L}_{3}-\mathrm{L}_{1}\right)+\mathrm{R}_{\mathrm{mot}}\left(\mathrm{L}^{2}{ }_{1} \mathrm{v}^{2}+\mathrm{R}_{\mathrm{rg}} \mathrm{L}_{3}+\mathrm{R}^{2}{ }_{\mathrm{sg}}\right.\right.$ $\mathrm{L}^{2}$ )

$\mathrm{C}_{3}=\mathrm{X}^{2}{ }_{\mathrm{mot}} \mathrm{R}_{\mathrm{rg}} \mathrm{v}\left(\mathrm{L}_{1}-\mathrm{L}_{2} \mathrm{~L}_{3}\right)-2 \mathrm{v}\left(\mathrm{X}^{2}{ }_{\text {mot }} \mathrm{R}_{\mathrm{sg}} \mathrm{L}^{2}{ }_{2}+\mathrm{R}_{\text {mot }} \mathrm{L}^{2}{ }_{1}\right)$

$$
\mathrm{C}_{4}=\mathrm{X}^{2}{ }_{\mathrm{mot}} \mathrm{R}_{\mathrm{rg}}\left(\mathrm{L}_{2} \mathrm{~L}_{3}-\mathrm{L}_{1}\right)+\mathrm{X}^{2}{ }_{\mathrm{mot}} \mathrm{R}_{\mathrm{sg}} \mathrm{L}^{2}{ }_{2}+\mathrm{R}_{\mathrm{mot}} \mathrm{L}^{2}
$$

$\mathrm{Z}_{1}=\mathrm{R}_{\mathrm{sg}} \mathrm{R}_{\mathrm{rg}}-\mathrm{F} *(\mathrm{~F}-\mathrm{V}) *\left(X_{s g} *\left(X_{r g}+X_{m g}\right)+X_{r g} * X_{m g}\right)$,

$$
\begin{aligned}
& Z_{2}=R_{s g} F\left(X_{s g}+X_{m g}\right)+R_{r g}(F-V)\left(X_{r g}+X_{m g}\right) \\
& Z_{4}=R_{r g} * M 2-\left(X_{r g}+X_{m g}\right) * F(F-V) * M 1
\end{aligned}
$$

$\underline{\text { With }}$

\section{Iron Losses}

$$
\begin{aligned}
& X_{\text {mg new }}=\frac{X_{m G} * R_{e G}}{X_{m G}+R_{e G}} \\
& L 1=X_{s g} *\left(X_{r g}+X_{m g} \text { new }\right)+X_{r g} * X_{\text {mg-new }}
\end{aligned}
$$$$
\mathrm{L} 2=\mathrm{X}_{\mathrm{rg}}+\mathrm{X}_{\mathrm{mg} \text {-new }},
$$$$
\mathrm{L} 3=\mathrm{X}_{\mathrm{sg}}+\mathrm{X}_{\mathrm{mg} \text {-new }}
$$ 


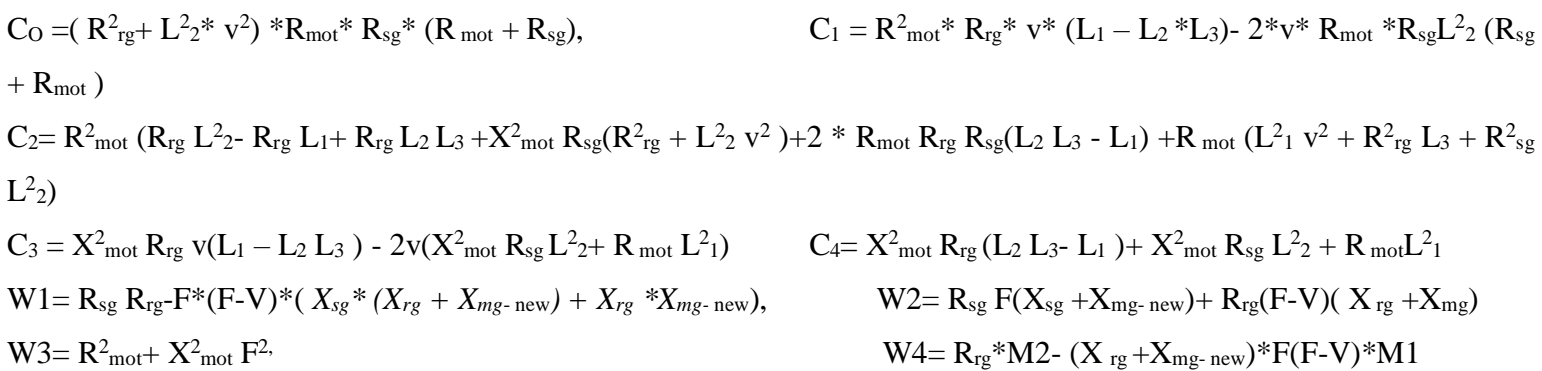

\section{REFERENCES}

[1] M. Godoy Simoes, Felix A. Farret, "Modeling and Analysis with Induction Generators," CRC Press, Taylor \& Francis Group, 2015.

[2] T.F. Chan., "Self-Excited Induction Generators Driven by Regulated and Unregulated Wind Turbines," IEEE transactions on energy conversion, vol. 11, no. 2, June 1996.

[3] K.S. Sandhu, S.P. Jain., "Steady State Operation Of Self-Excited Induction Generator With Varying Wind Speeds, " International journal of circuits, systems and signal processing, Issue-1,volume2,2008.

[4] K. Trinadha, and A. Kumar, "Performance of Wind Driven Induction Generator under Balanced/Unbalanced Load and Excitation," 978-1-4577-1002-5/11/2011 IEEE Member, IEEE.

[5] Sunil Kumar Goyal, D.K. Palwalia, "A Detailed Investigation On Performance Analysis Of Self-Excited Induction Generator, " 6th International Conference on Electronics, Computer and Manufacturing Engineering (ICECME'2017).

[6] Harish Kumar, Neel Kamal, " Steady-State analysis Self-excited Induction generator," International Journal of Soft Computing and Engineering (IJSCE) ISSN: 2231-2307, vol. 1, no. 5, November 2011.

[7] D. Seyoum, "The Dynamic Analysis And Control of A Self-Excited Induction Generator Driven By A Wind Turbine," A Thesis Submitted to The University of New South Wales For The Degree of Doctor of Philosophy, 2003.

[8] A. Abbou, M. Barara, A. Ouchatti, M. Akherraz, H. Mahmoudi., "Capacitance Required Analysis for Self-Excited Induction Generators, "Journal of Theoretical and Applied Information Technology 30th September 2013. vol. 55 no.3.

[9] A. Abbou, H. Mahmoudi, and M. Akherraz., "Analysis of SEIG For A Wind Pumping Plant Using Induction Motor," International Journal of Electrical and Computer Engineering, vol: 7, no: 6, 2013.

[10] A. K. Al. Jabri and A. L. Alolah., "Capacitor requirement for isolated self-excited induction generator", ZEE proceedings, vol. 137, pt. B, no. 3, May 1990.

[11] N. H. Malik and A. A. Mazi. "Capacitance requirements for isolated excited induction generators," IEEE Trans., 1987, EC-2 (I), pp. 62-69.

[12] R. Kumar T., V. Agarwal, P.S.V. Nataraj, "A Reliable and Accurate Calculation of Excitation Capacitance Value for an Induction Generator Based on Interval Computation Technique," International Journal of Automation and Computing 8(4), November 2011, pp 429-436.

[13] Eltamaly, A., "New Formula to Determine the Minimum Capacitance Required for Self-Exited Induction Generator," IEEE (2002).

[14] Mateo Bašić, Dinko Vukadinović, and Duško Lukač., "Novel Dynamic Model of Self-Excited Induction Generator with Iron Losses," International Journal of Mathematical Models and methods in applied Sciences Issue 2, Volume $5,2011$.

[15] M. Ouali, Mohamed Ben Ali Kamoun, Maher Chaabene, "Investigation On The Excitation Capacitor For A Wind Pumping Plant Using Induction Generator," Smart Grid and Renewable Energy, 2011, 2, 116-125doi:10.4236/sgre

[16] Mohamed Barara, Ahmed Abbou, Mohamed, Silviu Ionita, Emilian Lefter, Bogdan Enache. "Experimental Analysis on a Self-Excited Induction Generator for Standalone Wind Electric Pumping Stations," 12th International Conference on Development and Application Systems, Suceava, Romania, May 15-17, 2014.

[17] Al Al, Arfita Yuana Dewi, Antonov Bachtiar, Dwi Harinita.," An angle speed and thrust relationship of the quadcopter rotor," Indonesian Journal of Electrical Engineering and Computer Science, Vol. 13, No. 2, February 2019, pp. 469 474.

[18] S. G. Priyadharshini, C. Subramani, J. Preetha Roselyn.," An IOT based smart metering development for energy management system", International Journal of Electrical and Computer Engineering (IJECE), Vol. 9, No. 4, August 2019, pp. 3041 3050.

[19] Ahmed J. Ali1, Ziyad K. Farej2, Nashwan S. Sultan3.," Performance evaluation of a hybrid fuzzy logic controller based on genetic algorithm for three phase induction motor drive," International Journal of Power Electronics and Drive System (IJPEDS) vol. 10, no. 1, March 2019, pp. 117 127.

[20] Aderibigbe Israel Adekitan, Adeyinka Adewale, Alashiri Olaitan.," Determining the operational status of a three phase induction motor using a predictive data mining model," International Journal of Power Electronics and Drive System (IJPEDS) Vol. 10, No. 1, March 2019, pp. 93 103.

[21] Faiz, and S. Hasanzadeh., "Minimum Capacitance Requirement For Starting A SEIG," 14th International Symposium On Power Electronics, Ee 2007 Novi Sad, Republic Of Serbia, November 7th - 9th, 2007. 
[22] M. Ouali, M. Ben Ali Kamoun, M. Chaabene," Investigation on the Excitation Capacitor for a Wind Pumping Plant Using Induction Generator," Smart Grid and Renewable Energy, 2011, 2, pp 116-125.

[23] I. Daut, K. Anayet, M. Irwanto, N. Gomesh, M. Muzhar, M. Asri, Syatirah.," Parameters Calculation of 5 HP AC Induction Motor," Proceedings of International Conference on Applications and Design in Mechanical Engineering (ICADME) 11-13 October 2009, Batu Ferringhi, Penang, Malaysia.

[24] Ismel Kandilli "Experimental performance Evaluation of power Generation system using SEIG", elektronika ir elektrotechnika,Vol. 23, No1, 2017.

[25] Mohanty, A.K.; Yadav, K.B., "Estimation of excitation capacitance requirement of an isolated multi-phase induction generator for power generation, " International Journal of Power Electronics and Drive System, 2016, 7, 561-567.

\section{BIOGRAPHIES OF AUTHORS}

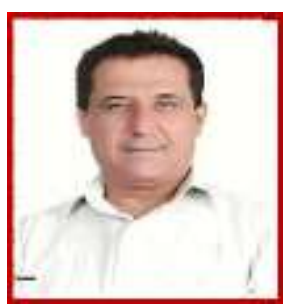

Mr. Hayder Hussein Kadhum earned his M.sc in the field of Electrical and Electronic Engineering from university of technology, Baghdad, Iraq, 2005, He completed his BSc in Electrical Engineering, university of technology, Baghdad, Iraq, 1990. His research interests includes power electronics, control power system, AC motor drives

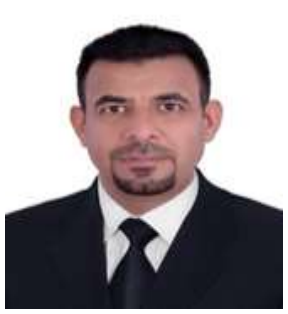

Mr. Ahmed Samawi Ghthwan earned his M.sc in the field of Electrical and Electronic Engineering from Eastern Mediterranean University, Turkey / North Cyprus2013. He has more than five years of experience in teaching. He completed his BSc in Electrical Engineering, university of technology, Baghdad, Iraq, 2001. His research interests includes power electronics, control power system, electronic system design and predictive current control modeling.

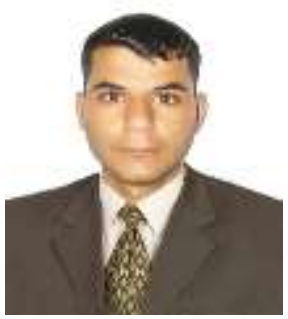

Mr. Hayder H. Emawi received the BSc. degree in Electrical Engineering from university of Babylon, Iraq in 2011 and the M.Sc. degree in Electrical Engineering (Power) from the University of South Australia, Australia, in 2016. His research interests the voltage stability application of electrical system approach to renewable power system generation. 